\title{
Survival and Differentiation of Cultured Dopaminergic Neurons Are Not Impaired by Chronic Stimulation of DA D-2 Autoreceptors
}

\author{
F.L. Van Muiswinkel, B. Drukarch ${ }^{1}$, H.W.M. Steinbusch and J.C. Stoof ${ }^{1}$ \\ Departments of Pharmacology and Neurology ${ }^{1}$, Free University Amsterdam, The Netherlands
}

Replacement of the degenerated dopaminergic input by grafted dopamine (DA) producing cells has been proposed as an effective therapy for Parkinson's disease (PD). However, results from clinical application of fetal DA grafts were rather disappointing since transplantation resulted only in slight functional improvement $/ 1 /$. Prolonged treatment with L-dopa or DA agonists might, via stimulation of DA D-2 autoreceptors, impair survival and/or differentiation of grafted neurons. Chronic treatment with Ldopa has been reported to impair survival and neurite outgrowth of cultured dopaminergic neurons $/ 2 /$. It is tempting to speculate that D-2 receptors are involved since $\mathrm{D}-2$ receptor activation not only leads to a decrease in the firing rate of dopaminergic neurons but also to an inhibition of the synthesis and release of DA. To investigate the role of D-2 receptors in the effect of L-dopa and the development of fetal dopaminergic neurons in general, knowledge about the expression of D-2 receptors on these neurons is a prerequisite. Therefore cultures were prepared from fetal rat ventral mesencephalon on gestational day 15 . Cultured dopaminergic neurons (identified by tyrosine hydroxylase $[\mathrm{TH}]$ immunocytochemistry) became more differentiated in the course of time and exhibited specific high-affinity uptake for $\left[{ }^{3} \mathrm{H}\right] \mathrm{DA}$. In the rat, activation of D-2 receptors, located on DA terminals, induces a decrease of the release of DA. Release data obtained in our cultures are given in the Figure. Previously accumulated $\left[{ }^{3} \mathrm{H}\right] \mathrm{DA}$ was released upon depolarization with $15 \mathrm{mM} \mathrm{K}^{+}$in a $\mathrm{Ca}^{2+}$. dependent manner. Potassium-evoked $\left[{ }^{3} \mathrm{H}\right] \mathrm{DA}$ release could be inhibited by both the selective D-2 receptor agonists LY171555 (Quinpirole, LY) and N0437, in a concentration dependent way. The effect of LY171555 was blocked by the

$D A D-2$ receptor mediated inhibition of $K^{+}$-evoked $\left.{ }^{3} H\right] D A$ release from cultured $D A$ neurons
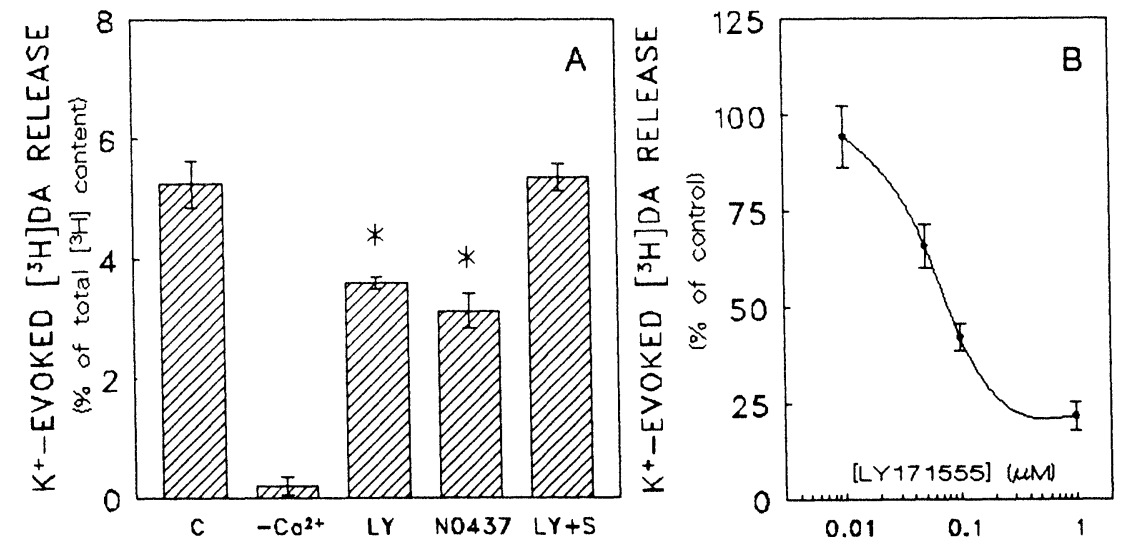

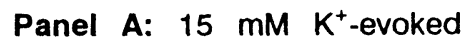
release was determined in 7 day old cultures under $\mathrm{Ca}^{2+}$ free conditions $\left(-\mathrm{Ca}^{2+}\right)$ and in the absence $(C)$ or presence of the selective $D-2$ receptor agonist LY $171555(L Y, 1 \mu M)$ or N0437 $(0.1 \mu \mathrm{M})$. The effect of $1 \mu \mathrm{M}$ LY171555 was blocked by $1 \mu M$ Sulpiride $(L Y+S)$.

Panel B: Concentrationdependency of the effect of LY171555 on the $\mathrm{K}^{+}$-evoked release of $\left[{ }^{3} \mathrm{H}\right] \mathrm{DA}$ from 17 day old cultures. Values represent means $\pm \operatorname{SEM}(n=4)$. 
selective D-2 antagonist sulpiride (LY+S). These observations are indicative of the expression of functional D-2 receptors. Under our culture conditions, treatment with $10 \mu \mathrm{M}$ L-dopa for 7 days abolished the uptake capacity for $\left[{ }^{3} \mathrm{H}\right] \mathrm{DA}$, indicative of a massive degeneration of dopaminergic neurons. Subsequently, the effects of treatment with various concentrations of LY171555 or sulpiride (to block endogenous DA) were studied to elucidate the role of D-2 receptors. The stability of both drugs (determined with a bioassay) guaranteed a state of either chronic stimulation or blockade of D-2 receptors, when administered daily. Treatment for 7 consecutive days did not lead to any change in total protein content, the number of $\mathrm{TH}$ immunoreactive neurons or the uptake capacity for $\left[{ }^{3} \mathrm{H}\right] \mathrm{DA}$. Moreover, no apparent differences were observed in the morphology of either dopaminergic or non-dopaminergic neurons present in control or drug-treated cultures. Also, treatment for longer periods (up to 14 days) did not alter the $\left[{ }^{3} \mathrm{H}\right] \mathrm{DA}$ uptake capacity of the cultures.

It is concluded that (1) cultured DA neurons express D-2 receptors functionally coupled to the inhibition of DA release, and (2) chronic stimulation or blockade of D-2 receptors does not impair survival or differentiation of cultured DA neurons.

\section{REFERENCES}

1. Lindvall et al. Science 1990;1 247: 547-577.

2. Steece-Collier et al. Exp Neurol 1990; 110: 201-208. 

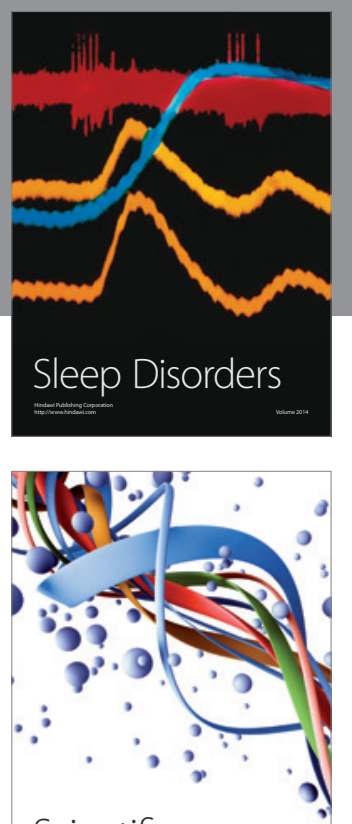

Scientifica
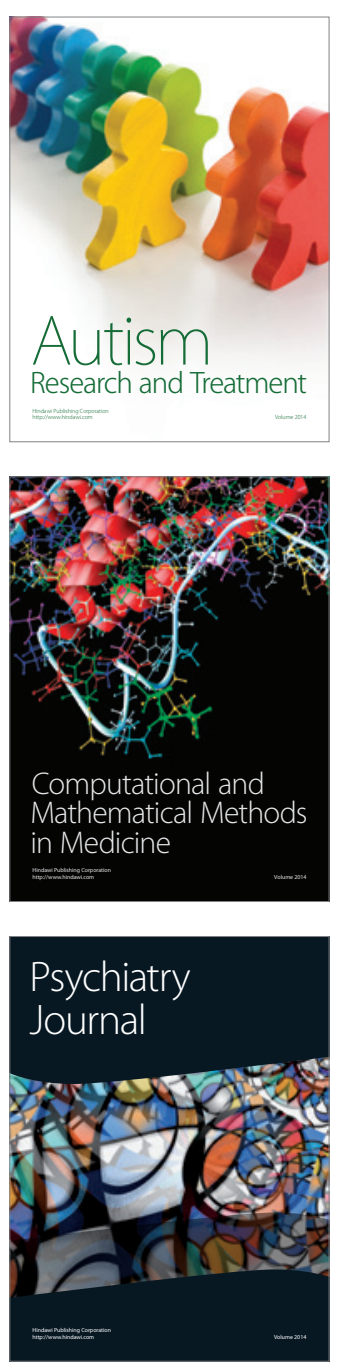
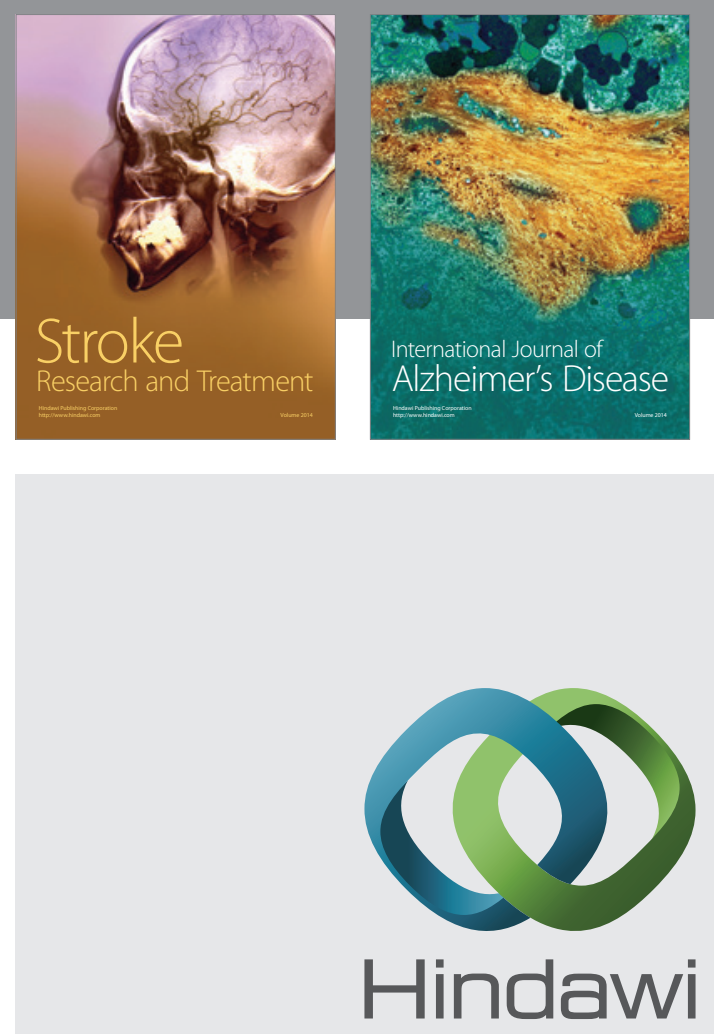

Submit your manuscripts at

http://www.hindawi.com
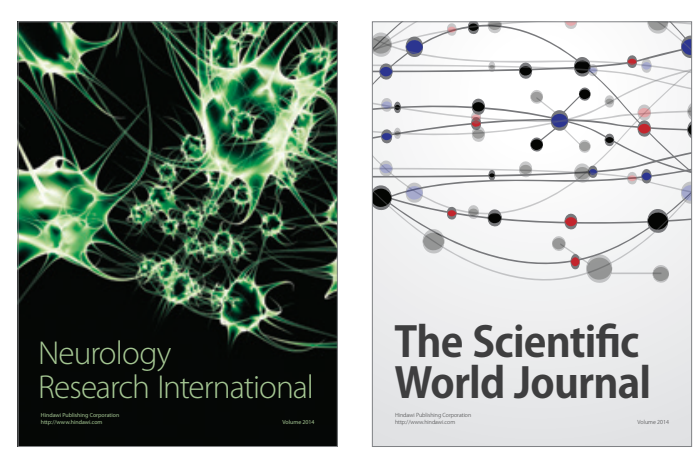

The Scientific World Journal

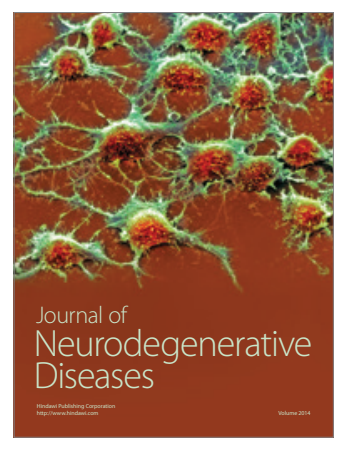

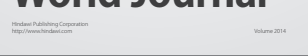

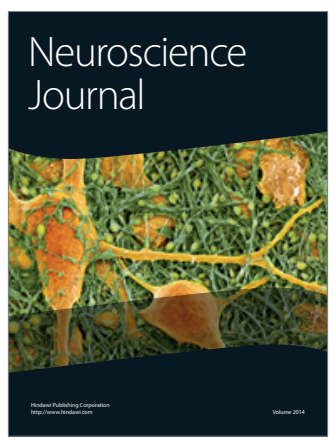

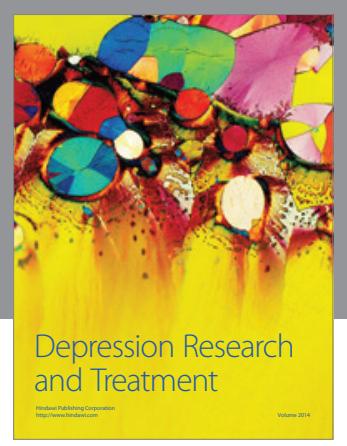
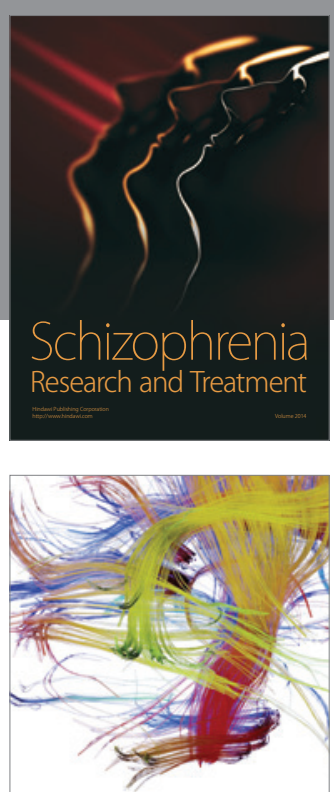

Brain Science

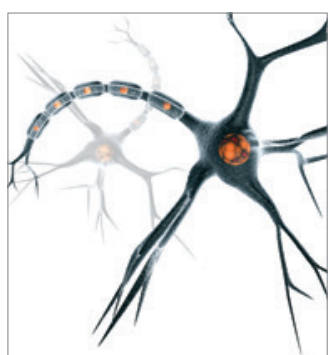

Neural Plasticity
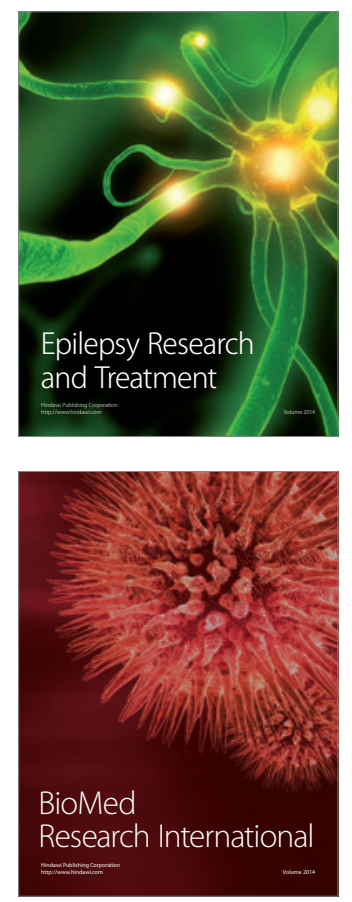

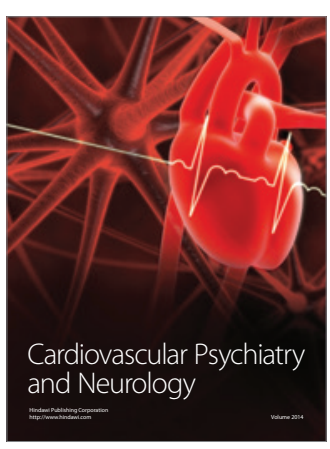

Parkinson's

Disease
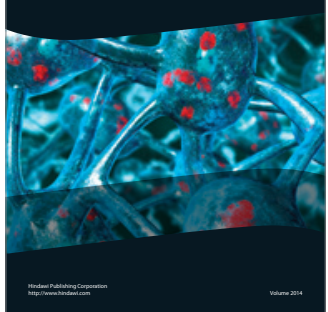